\title{
A Robust Resource Allocation Framework Using Hybrid Bat Algorithm (HBA)
}

\author{
A. Jemshia Miriam ${ }^{1}$, Dr. R. Saminathan ${ }^{2}$, Dr. S. Chakaravarthi ${ }^{3}$ \\ ${ }^{1}$ Research Scholar, Department of Computer Science and Engineering, Annamalai University, \\ Annamalai Nagar, Tamilnadu, India, jemshiamiriamajs@gmail.com \\ ${ }^{2}$ Associate Professor, Department of Computer Science and Engineering, Annamalai University, \\ Annamalai Nagar, Tamilnadu, India, samiaucse@yahoo.com \\ ${ }^{3}$ Professor \& Head, Department of Computer Science and Engineering, Velammal Engineering College, \\ Chennai, Tamilnadu, India, chakra2603@gmail.com
}

\begin{abstract}
In the era of cloud computing and IT paradigm the resource allocation and over provisioning has introduced lot of automation in terms of manual and automated process. However, most of the cloud resource providers focus more on the effective resource allocation with better pricing. Recent solution adapted for cloud resource allocation and management leads to task level sub optimal performance due to on-demand varying job requirements. To address this issue in the existing cloud resource scheduling and allocation, a novel fine-grained scheduling solution is proposed. The key idea of the proposed solution is to utilize Hybrid Bat algorithm (HBA). Further, the HBA is a modified BAT algorithm. HBA algorithm is privileged to execute in the middleware and tasks allocation subjected to individual physical and virtual machines are completely handled for time critical jobs with fixed and varying deadline. The proposed resource allocation framework has multi-tendency support for all forms of cloud (public, private and hybrid). The entire framework is deployed and validated using Amazon EC2 instance with spark cluster 20-node. The experimental results proven that the proposed HBA based framework is robust and offers a maximum range of high resource utilization.
\end{abstract}

Key words: Social Bat Algorithm, Bat Algorithm, Cloud resource scheduling

\section{INTRODUCTION}

Cloud computing refers to the servers that can be accessed online over the internet. Cloud computing in short is delivering of hosted services over the internet like data storage, accessing data [1]. Before Cloud computing, we had many issues like buying lot of servers in order to host a website, maintaining and monitoring a server is always a tough job. Buying more servers is always a costly option as buying more servers means maintaining more servers and for maintains more servers; we need to hire a greater number of people, which is again expensive [2-3]. The traffic is never constant, you might have to buy more number of servers for the varying traffic on the website but it is not always constant, the server is idle most of the time, which means, we are buying more amounts of servers for the traffic, which is idle most of the time [4]. Before cloud, to create an application or a website we needed a team of experts to install, configure, test, run, secure and update them which means we need to hire a team to do that, so individuals were not able to create applications and websites, where as it is a completely different scenario now. It used to be hard for a big company to create and maintain hundreds of applications, there will not be a chance for small and medium companies to build that large amount of applications or websites. With Cloud Computing, even an individual can build an application as there will not be any problem of managing software and hardware as it will be maintained by the service providers. Cloud Computing is on-demand, which means you can have the control over turning resources on or off, which ensures that there is no lack of resources [5-6]. Cloud Computing is cost effective- We only pay for what we use. Cloud Computing is accessible from anywhere, which makes it easier to use data [7].

In this cloud era, the resource management plays a huge role in both the client and service provider site in terms of cost cutting and reduction. The resource management system mechanism helps coordinate IT resources in response to management actions performed by both cloud consumers and cloud providers. Present day heterogeneous resources are located in various geographical locations requiring security-aware resource management to handle security threats. However, existing techniques are unable to protect systems from security attacks. To provide a secure cloud service, a security-based 
resource management technique is required that manages cloud resources automatically and delivers secure cloud services [8]. Core to this system is the Virtual Infrastructure Manager (VIM) that coordinates the server hardware so that virtual server instances can be created from the most expedient underlying physical server. To address this, this research work addresses a secured framework, which involves context aware resource allocation [9].

Contributions in this paper:

- A novel algorithm is proposed by modifying the existing state of the art BAT Algorithm.

- The proposed Social Bat Algorithm is modified and the experimentation is proven that the proposed HBA is better than the particle swarm optimization and parallel genetic algorithm.

- HBA uses an optimal best solution obtained when processing the local solutions. Further, the proposed framework is tested in all real time networks and the results confirm that the proposed HBA is optimal.

- The proposed HBA utilizes the effective handling of optimization with best solutions, which avoids overfitting and under fitting problems.

- The proposed HBA is a hybrid bat algorithm and completely deployed and validated in Hadoop Cluster.

The organization of this paper is as follows: Section II deals with the literature survey. Section III proposes the cloud resource management framework. This section explains the HBA algorithm. Section IV deals with the experimental setup. The penultimate section deals with the result and performance analysis. Finally, the paper is concluded in the Section VI.

\section{LITERATURE SURVEY}

From the literature survey, it is observed that enormous amount of algorithms for cloud resource scheduling was developed in recent days [13][14][15]. Out of those algorithms, evolutionary algorithm based solutions found to give promising results for cloud scheduling. In this section, a detailed survey is given based on the evolutionary algorithms.

Bat algorithm is one of the best evolutionary algorithms in the decade. The algorithm works based on the principle of echo localization. This echo localization property is used by BATs for hunting and obstacle finding. The other common evolutionary algorithm widely used for resource scheduling is particle swarm optimization. Maria Alejandra Rodriguez and RajkumarBuyya [1] proposed an approach on deadline based resource provisioning and scheduling. The key idea of their work is to utilize particle swarm optimization technique for efficient resource provisioning. They validated their approach in Cloudsim and presented an outstanding result.

Qi Zhang et al presented a novel model called prism, which is a Fine-Grained Resource-Aware Scheduling scheme for MapReduce [2]. In their work, the authors validated various case scenarios in which tasks with high varying resource requirements were perfectly handled and achieved betterment in execution of such process in terms of scheduling, computation and fast processing. To achieve this they introduced a novel Fine-grained resource aware scheduling scheme, which divides the tasks into multiple phases, and each phases are then handled appropriately. To the point, each fine-segregated phase holds the information such as resource usage profile, which will help the admin to know the total resource utilization and consumption [10].

In addition to the above contribution, Xiaomin Zhu proposed Real-Time Tasks Oriented Energy-Aware Scheduling in Virtualized Clouds. The key of their work is to perform guaranteed system schedulability. They proposed task-oriented energy consumption model. From the literature survey, it is observed that the existing methodologies for cloud resource provisioning is not efficient and requires greater computation [11-12]. Most of the algorithmic cases reported the efficiency and execution time of the algorithm. Hence, there is a pressing need for an efficient algorithm for cloud resource allocation and scheduling. To address this issue, this paper proposed a novel framework utilizing the Social Bat Algorithm, which is a hybrid bat algorithm for cloud resource allocation. The novelty of the proposed Social Bat Algorithm is that the algorithm utilizes the effective handling of optimization with best solutions, which avoids overfitting and under fitting problems. The proposed algorithm always sticks to the best optimal solution which avoids overfitting and under fitting problems.

\section{PROPOSED FRAMEWORK}

The proposed framework for cloud resource management as shown in the Fig. 1 is implemented using Hybrid Bat Algorithm (HBA). HBA is a novel and hybrid algorithm, which relies on BAT algorithm. HBA also work based on the echo localization, a technique used in BAT algorithm. The key idea is to use sonar waves to detect food and obstacles with the boundary range. The motto of this 
work is to utilize this hybrid BAT algorithm for efficient resource scheduling. The rule set governed for HBA is stated as follows.

There is no path restriction for bats to fly, where the velocity is defined by $\mathrm{V}_{\mathrm{i}}$ at position $\mathrm{X}_{\mathrm{i}}$.

The frequency is fixed in order to communicate within the population whereas the wavelength can be adjusted automatically based on the target locality.

The loudness with the echo can be varied from the higher pitch to the lower pitch. The detailed illustration of the parameters considered for the algorithm is stated in the section 'Algorithm' and the pictorial representation is given in the Fig. 2.

The proposed HBA is designed for optimizing the resource allocation solutions in order to avoid resource wastage and to increase the cost of income.

The proposed HBA is applied for resource scheduling for efficient optimization in resource allocation.

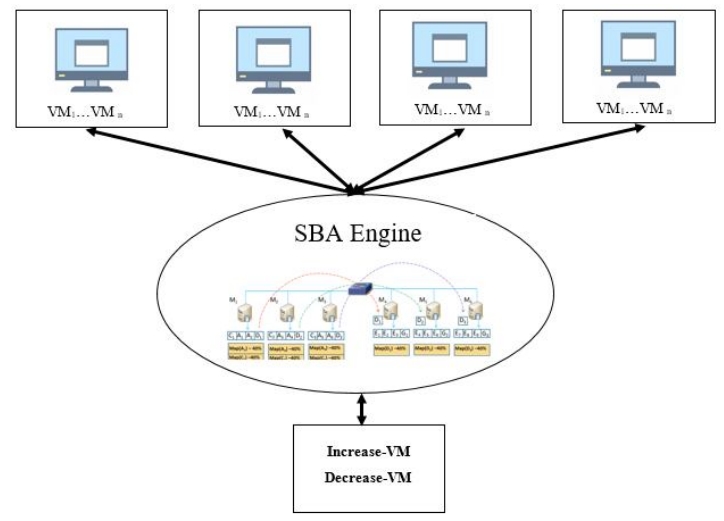

Figure 1: Architecture of the Proposed Framework

Fig. 1 shows the architecture of the proposed framework. The total population i.e., the bats utilizes echo localization technique to find the distance between food and obstacles.

\section{Algorithm:}

Algorithmic part of this section contains two main components namely i) features ii) algorithm

Features considered for experimentation are listed as follows

- Population space or dimension

- Population generation

- Loudness

- Pulse rate

- Frequency min

- Frequency max
- Lower bound

- Upper bound

Algorithm

Fig. 2 shows the algorithmic part of the proposed HBA.

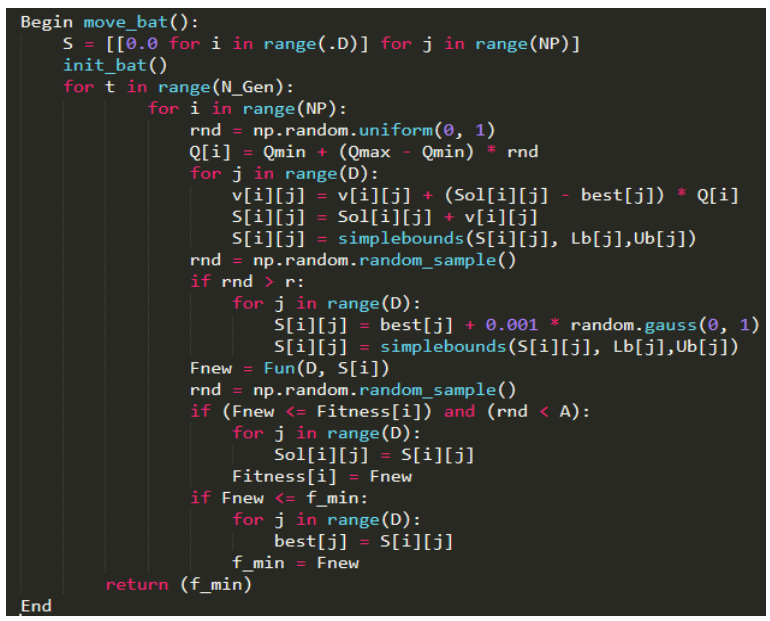

Figure 2: Algorithm of Social BAT Movement

\section{EXPERIMENTAL SETUP}

The proposed framework is experimented and validated in the simulated test bed. The test bed is executed in a machine with 64 GB RAM, Intel Xeon processor running in Ubuntu Server Operating system. The entire simulation is made using python and the simulation executed for more than 20 hours. The entire results were plotted in the three dimensional plot with the considered parameters such as resource wastage, file unavailability and power consumption. The results were obtained for the allocation in VM in the individual physical machine. Table 1 - Table 4 shows the resource available plot and allocation-scheduling plot. Multi VMs are allowed to run inside physical machine. Each VM running in the PM has several VMs execution on it. In addition to the above setup, we configured with different variants of VMs. VM pricing is also estimated in order to estimate the total cost incurred during the allocation. This will help us to estimate the loss incurred by the cloud service provider during the idle wait happening while allocation and scheduling.

The workflow of the propose framework is also validated based on the processing time of different VMs. Each VMs configuration is listed in the Tables $1-4$. Further, the validation is calculated based on the fixed deadline for individual physical machine. The deadline period is restricted not to get relaxed in order to estimate the exact loss incurred during the allocation or idle wait during scheduling. 
A. Jemshia Miriam et al., International Journal of Emerging Trends in Engineering Research, 8(9), September 2020, 5917 - 5924

Table 1: Resource Availability on Physical Machine 1

\begin{tabular}{|c|c|c|}
\hline $\begin{array}{l}\text { Physical } \\
\text { Machine }\end{array}$ & VM1 & VM2 \\
\hline \multirow{2}{*}{ PM1 } & $\mathrm{VM}(25)$ & $\mathrm{VM}(25)$ \\
\cline { 2 - 3 } & $\mathrm{VM}(50)$ & $\mathrm{VM}(50)$ \\
\cline { 2 - 3 } & $\mathrm{VM}(75)$ & $\mathrm{VM}(75)$ \\
\hline
\end{tabular}

Table 2: Resource Availability on Physical Machine 2

\begin{tabular}{|c|c|c|c|}
\hline $\begin{array}{c}\text { Physical } \\
\text { Machine }\end{array}$ & $\mathrm{VM} 1$ & $\mathrm{VM} 2$ & $\mathrm{VM} 3$ \\
\hline \multirow{3}{*}{$\mathrm{PM} 2$} & $\mathrm{VM}(100)$ & $\mathrm{VM}(100)$ & $\mathrm{VM}(100)$ \\
\cline { 2 - 4 } & $\mathrm{VM}(125)$ & $\mathrm{VM}(125)$ & $\mathrm{VM}(125)$ \\
\cline { 2 - 4 } & $\mathrm{VM}(150)$ & $\mathrm{VM}(150)$ & $\mathrm{VM}(150)$ \\
\hline
\end{tabular}

Table 3: Resource Availability on Physical Machine 3

\begin{tabular}{|c|c|c|c|}
\hline $\begin{array}{c}\text { Physical } \\
\text { Machine }\end{array}$ & VM1 & VM2 & VM3 \\
\hline \multirow{3}{*}{ PM3 } & $\mathrm{VM}(150)$ & $\mathrm{VM}(150)$ & $\mathrm{VM}(150)$ \\
\cline { 2 - 4 } & $\mathrm{VM}(175)$ & $\mathrm{VM}(175)$ & $\mathrm{VM}(175)$ \\
\cline { 2 - 4 } & $\mathrm{VM}(200)$ & $\mathrm{VM}(200)$ & $\mathrm{VM}(200)$ \\
\hline
\end{tabular}

Table 4: Resource Availability on Physical Machine 4

\begin{tabular}{|c|c|c|c|}
\hline $\begin{array}{c}\text { Physical } \\
\text { Machine }\end{array}$ & VM1 & VM2 & VM3 \\
\hline \multirow{3}{*}{ PM4 } & $\mathrm{VM}(200)$ & $\mathrm{VM}(200)$ & $\mathrm{VM}(200)$ \\
\cline { 2 - 4 } & $\mathrm{VM}(225)$ & $\mathrm{VM}(225)$ & $\mathrm{VM}(225)$ \\
\cline { 2 - 4 } & $\mathrm{VM}(250)$ & $\mathrm{VM}(250)$ & $\mathrm{VM}(250)$ \\
\hline
\end{tabular}

\section{RESULT ANALYSIS}

The experimental results of the proposed framework are given in the tables from Table 5 to Table 14. The effectiveness of the proposed HBA is validated with the various benchmarks.

The benchmarked strategies used in the HBA are levy, sphere, rosenbrock, schwefel, rastrigin, griewank, ridge, salomon, whitley, ackley. Fig. 3 shows the results of benchmarked strategies for BA and HBA for the min parameter. Fig. 4 shows the results of benchmarked strategies for BA and HBA for the max parameter.

Fig. 5 shows the results of benchmarked strategies for BA and HBA for the mean parameter. Fig. 6 shows the results of benchmarked strategies for BA and HBA for the median parameter.

Fig. 7 shows the results of benchmarked strategies for $\mathrm{BA}$ and HBA for the standard deviation parameter.

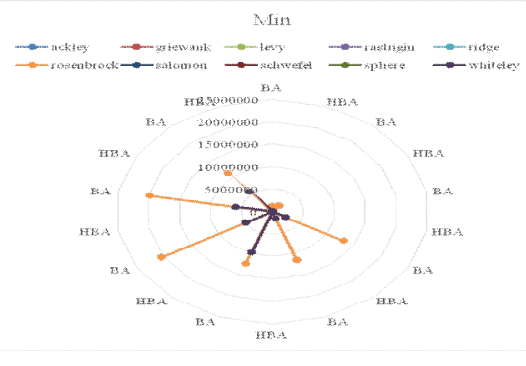

Figure 3: BA vs HBA Results - Min Parameter

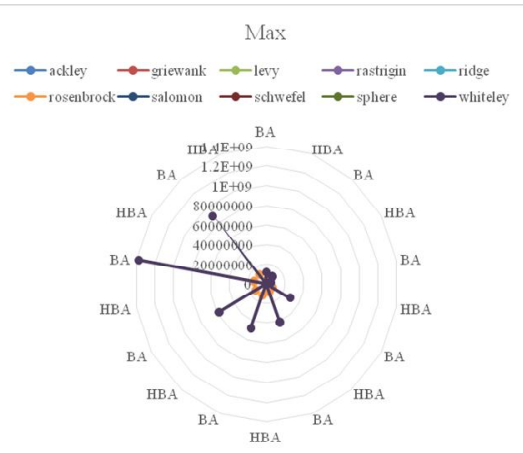

Figure 4: BA vs HBA Results - Max Parameter

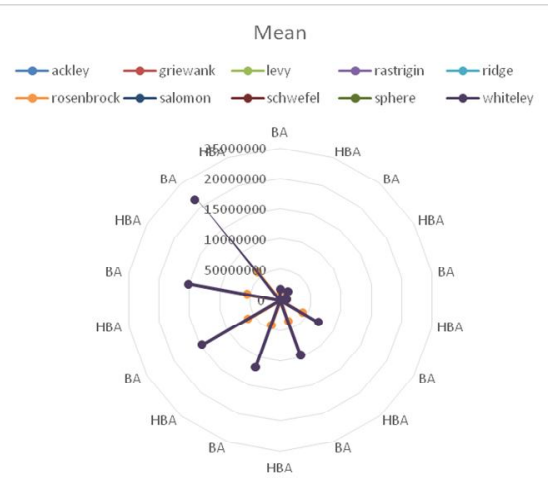

Figure 5: BA vs HBA Results - Mean Parameter

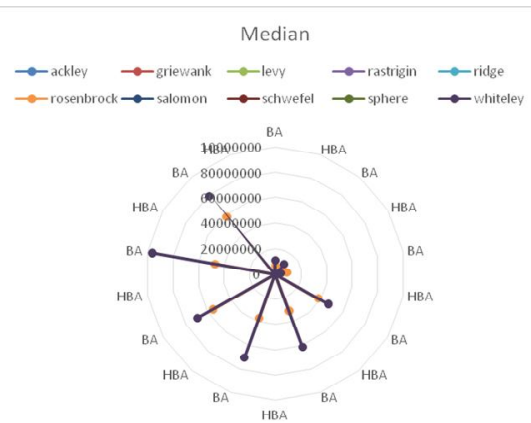

Figure 6: BA vs HBA Results - Median Parameter 
A. Jemshia Miriam et al., International Journal of Emerging Trends in Engineering Research, 8(9), September 2020, 5917 - 5924

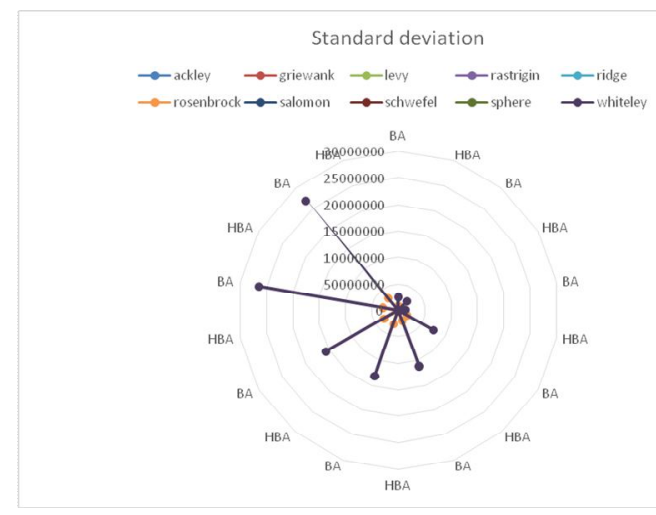

Figure 7: BA vs HBA Results - Standard Deviation Parameter

Table 5: Statistical based Comparative Analysis of Ackley Benchmark Function

\begin{tabular}{|l|c|c|c|c|c|c|c|}
\hline Alg. & Bench. & Meas. & Min & Max & Mean & Median & Std \\
\hline BA & ackley & $\mathrm{D}=10 \mathrm{~Np}=20$ & 12.95681395 & 19.03018126 & 16.43930662 & 16.74286 & 1.570757 \\
\hline HBA & ackley & $\mathrm{D}=10 \mathrm{~Np}=20$ & $7.42338 \mathrm{E}-07$ & 2.814349981 & 0.65320626 & $2.31 \mathrm{E}-06$ & 0.819045 \\
\hline BA & ackley & $\mathrm{D}=10 \mathrm{~Np}=30$ & 13.41228052 & 18.24848154 & 16.47125976 & 17.04906 & 1.340698 \\
\hline HBA & ackley & $\mathrm{D}=10 \mathrm{~Np}=30$ & $4.53012 \mathrm{E}-07$ & 3.574239616 & 1.083724707 & 1.155149 & 1.121569 \\
\hline BA & ackley & $\mathrm{D}=10 \mathrm{~Np}=50$ & 14.04885709 & 19.50722109 & 16.87788528 & 17.0948 & 1.128057 \\
\hline HBA & ackley & $\mathrm{D}=10 \mathrm{~Np}=50$ & $5.94777 \mathrm{E}-07$ & 2.814349981 & 1.032712165 & 1.155149 & 0.975228 \\
\hline BA & ackley & $\mathrm{D}=20 \mathrm{~Np}=20$ & 16.30478118 & 19.4487542 & 17.90237446 & 17.85586 & 0.688578 \\
\hline HBA & ackley & $\mathrm{D}=20 \mathrm{~Np}=20$ & 1.839993476 & 6.31580377 & 3.604944489 & 3.489881 & 1.276403 \\
\hline BA & ackley & $\mathrm{D}=20 \mathrm{~Np}=30$ & 17.214451 & 19.51799151 & 17.98783775 & 17.86543 & 0.58904 \\
\hline HBA & ackley & $\mathrm{D}=20 \mathrm{~Np}=30$ & 1.155148503 & 7.294016103 & 2.985236878 & 2.922803 & 1.334953 \\
\hline BA & ackley & $\mathrm{D}=20 \mathrm{~Np}=50$ & 15.87159318 & 19.46855449 & 17.98837529 & 17.98534 & 0.724352 \\
\hline HBA & ackley & $\mathrm{D}=20 \mathrm{~Np}=50$ & 1.646223633 & 5.977244539 & 3.158546452 & 2.920986 & 1.197545 \\
\hline
\end{tabular}

Table 6: Statistical based Comparative Analysis of Griewank Benchmark Function

\begin{tabular}{|c|c|c|c|c|c|c|c|}
\hline Alg. & Bench. & Meas. & Min & Max & Mean & Median & Std \\
\hline BA & griewank & $\mathrm{D}=10 \mathrm{~Np}=20$ & 1.543100219 & 4.571646101 & 2.995083965 & 2.821429 & 0.732493 \\
\hline HBA & griewank & $\mathrm{D}=10 \mathrm{~Np}=20$ & 0.032013428 & 0.437065819 & 0.13124492 & 0.110651 & 0.085948 \\
\hline BA & griewank & $\mathrm{D}=10 \mathrm{~Np}=30$ & 1.852639427 & 4.95855177 & 3.21632097 & 3.248924 & 0.803675 \\
\hline HBA & griewank & $\mathrm{D}=10 \mathrm{~Np}=30$ & 0.012320989 & 0.757460717 & 0.15550507 & 0.125512 & 0.147123 \\
\hline BA & griewank & $\mathrm{D}=20 \mathrm{~Np}=20$ & 4.495300461 & 9.5402401 & 7.171027262 & 7.125763 & 1.43381 \\
\hline HBA & griewank & $\mathrm{D}=20 \mathrm{~Np}=20$ & $2.22045 \mathrm{E}-16$ & 0.098055013 & 0.025859073 & 0.02459 & 0.020506 \\
\hline BA & griewank & $\mathrm{D}=20 \mathrm{~Np}=30$ & 2.997100035 & 10.04286618 & 6.30077734 & 5.838527 & 1.781593 \\
\hline HBA & griewank & $\mathrm{D}=20 \mathrm{~Np}=30$ & $7.21645 \mathrm{E}-15$ & 0.120074052 & 0.032317282 & 0.029481 & 0.029357 \\
\hline
\end{tabular}


A. Jemshia Miriam et al., International Journal of Emerging Trends in Engineering Research, 8(9), September 2020, 5917 - 5924

Table 7: Statistical based Comparative Analysis of Levy Benchmark Function

\begin{tabular}{|l|l|l|r|r|r|r|r|}
\hline Alg. & \multicolumn{1}{|c|}{ Bench. } & \multicolumn{1}{c|}{ Meas. } & \multicolumn{1}{c|}{ Min } & \multicolumn{1}{c|}{ Max } & \multicolumn{1}{c|}{ Mean } & \multicolumn{1}{c|}{ Median } & Std \\
\hline BA & levy & $\mathrm{D}=10 \mathrm{~Np}=20$ & $6.68271 \mathrm{E}-07$ & 1.032367083 & 0.347613475 & 0.090845 & 0.426536 \\
\hline HBA & levy & $\mathrm{D}=10 \mathrm{~Np}=20$ & $8.6269 \mathrm{E}-17$ & 0.850676406 & 0.059463531 & $1.87 \mathrm{E}-15$ & 0.173929 \\
\hline BA & levy & $\mathrm{D}=10 \mathrm{~Np}=30$ & $4.79581 \mathrm{E}-07$ & 0.991519002 & 0.162691623 & $4.02 \mathrm{E}-06$ & 0.333619 \\
\hline HBA & levy & $\mathrm{D}=10 \mathrm{~Np}=30$ & $8.25863 \mathrm{E}-17$ & 0.181689108 & 0.039971604 & $6.32 \mathrm{E}-15$ & 0.052971 \\
\hline BA & levy & $\mathrm{D}=20 \mathrm{~Np}=20$ & $2.34072 \mathrm{E}-06$ & 2.872842893 & 0.968379018 & 0.893494 & 0.909044 \\
\hline HBA & levy & $\mathrm{D}=20 \mathrm{~Np}=20$ & $7.2699 \mathrm{E}-19$ & 1.792197365 & 0.350836641 & 0.090845 & 0.491524 \\
\hline BA & levy & $\mathrm{D}=20 \mathrm{~Np}=30$ & $3.29245 \mathrm{E}-06$ & 1.927657309 & 0.563721111 & 0.272573 & 0.621769 \\
\hline HBA & levy & $\mathrm{D}=20 \mathrm{~Np}=30$ & $3.96103 \mathrm{E}-18$ & 1.701352811 & 0.211094634 & 0.181689 & 0.387035 \\
\hline
\end{tabular}

Table 8: Statistical based Comparative Analysis of Rastrigin Function

\begin{tabular}{|l|l|l|r|r|r|r|c|}
\hline Alg. & Bench. & Meas. & \multicolumn{1}{c|}{ Min } & \multicolumn{1}{c|}{ Max } & Mean & \multicolumn{1}{c|}{ Median } & \multicolumn{1}{c|}{ Std } \\
\hline BA & rastrigin & $\mathrm{D}=10 \mathrm{~Np}=20$ & 13.9298977 & 101.485199 & 44.01707144 & 36.81367 & 21.81012 \\
\hline HBA & rastrigin & $\mathrm{D}=10 \mathrm{~Np}=20$ & 3.979836434 & 22.88399826 & 11.82233731 & 11.9395 & 4.781466 \\
\hline $\mathrm{BA}$ & rastrigin & $\mathrm{D}=10 \mathrm{~Np}=30$ & 12.93462382 & 69.64698799 & 38.12693548 & 36.81358 & 16.53619 \\
\hline $\mathrm{BA}$ & rastrigin & $\mathrm{D}=20 \mathrm{~Np}=20$ & 36.81490846 & 142.2796348 & 88.67176142 & 93.5275 & 28.43502 \\
\hline HBA & rastrigin & $\mathrm{D}=20 \mathrm{~Np}=20$ & 21.8890791 & 69.64681497 & 46.44457022 & 41.78822 & 12.78918 \\
\hline BA & rastrigin & $\mathrm{D}=20 \mathrm{~Np}=30$ & 41.78951117 & 166.1586778 & 88.87070429 & 74.62325 & 36.19036 \\
\hline
\end{tabular}

Table 9: Statistical based Comparative Analysis of Ridge Function

\begin{tabular}{|l|l|l|c|c|c|c|c|}
\hline \multicolumn{1}{|c|}{ Alg. } & Bench. & Meas. & Min & Max & Mean & Median & Std \\
\hline BA & ridge & $\mathrm{D}=10 \mathrm{~Np}=20$ & 1207.791395 & 7924.437666 & 4134.581048 & 3928.559 & 1812.34 \\
\hline HBA & ridge & $\mathrm{D}=10 \mathrm{~Np}=20$ & $2.93919 \mathrm{E}-07$ & $6.89773 \mathrm{E}-05$ & $7.30567 \mathrm{E}-06$ & $1.98 \mathrm{E}-06$ & $1.4 \mathrm{E}-05$ \\
\hline BA & ridge & $\mathrm{D}=10 \mathrm{~Np}=30$ & 2013.497515 & 8748.925565 & 4767.739665 & 4596.844 & 1607.933 \\
\hline BA & ridge & $\mathrm{D}=20 \mathrm{~Np}=20$ & 6078.217716 & 27218.41793 & 14134.79567 & 13916.41 & 4572.348 \\
\hline HBA & ridge & $\mathrm{D}=20 \mathrm{~Np}=20$ & 0.002534585 & 0.067033432 & 0.020681288 & 0.013499 & 0.01811 \\
\hline BA & ridge & $\mathrm{D}=20 \mathrm{~Np}=30$ & 3516.182348 & 25494.74263 & 12474.47509 & 11510.14 & 4908.982 \\
\hline
\end{tabular}

Table 10: Statistical based Comparative Analysis of Rosenbrock Function

\begin{tabular}{|l|c|c|c|c|c|r|c|}
\hline Alg. & Bench. & Meas. & Min & Max & Mean & \multicolumn{1}{c|}{ Median } & \multicolumn{1}{c|}{ Std } \\
\hline BA & rosenbrock & $\mathrm{D}=10 \mathrm{~Np}=20$ & 1179657.884 & 33527106.07 & 9724989.174 & 7050440 & 8181975 \\
\hline HBA & rosenbrock & $\mathrm{D}=10 \mathrm{~Np}=20$ & 0.008163632 & 71.15021665 & 5.607646668 & 2.479962 & 13.78989 \\
\hline BA & rosenbrock & $\mathrm{D}=10 \mathrm{~Np}=30$ & 1656245.723 & 27527151.43 & 9745564.166 & 6682500 & 7823574 \\
\hline BA & rosenbrock & $\mathrm{D}=20 \mathrm{~Np}=20$ & 13087223 & 77426325.36 & 40923505.07 & 38091583 & 18213488 \\
\hline HBA & rosenbrock & $\mathrm{D}=20 \mathrm{~Np}=20$ & 0.017135306 & 111.2791496 & 15.9941995 & 10.4267 & 23.99042 \\
\hline BA & rosenbrock & $\mathrm{D}=20 \mathrm{~Np}=30$ & 11539319.1 & 89858820.08 & 37260634.7 & 30673234 & 20346744 \\
\hline
\end{tabular}

Table 11: Statistical based Comparative Analysis of Salomon Function

\begin{tabular}{|c|c|c|c|c|c|c|c|}
\hline Alg. & Bench. & Meas. & Min & Max & Mean & Median & Std \\
\hline BA & salomon & $\mathrm{D}=10 \mathrm{~Np}=20$ & 380.9147749 & 1452.423593 & 927.8252177 & 909.0687 & 260.549 \\
\hline HBA & salomon & $\mathrm{D}=10 \mathrm{~Np}=20$ & 0.099495906 & 1.591924382 & 0.4457406 & 0.397983 & 0.326369 \\
\hline BA & salomon & $\mathrm{D}=10 \mathrm{~Np}=30$ & 377.0942963 & 1810.693347 & 904.2148048 & 961.2369 & 370.6271 \\
\hline BA & salomon & $\mathrm{D}=20 \mathrm{~Np}=20$ & 1126.797068 & 3671.3748 & 2180.988738 & 2077.56 & 556.607 \\
\hline HBA & salomon & $\mathrm{D}=20 \mathrm{~Np}=20$ & 1.591924379 & 12.03837243 & 4.652300226 & 3.581799 & 2.954069 \\
\hline BA & salomon & $\mathrm{D}=20 \mathrm{~Np}=30$ & 1392.05862 & 3375.818632 & 2273.522364 & 2247.024 & 503.3671 \\
\hline
\end{tabular}


A. Jemshia Miriam et al., International Journal of Emerging Trends in Engineering Research, 8(9), September 2020,5917 - 5924

Table 12: Statistical based Comparative Analysis of Schwefel Function

\begin{tabular}{|l|c|c|r|r|r|c|c|}
\hline Alg. & Bench. & Meas. & \multicolumn{1}{c|}{ Min } & Max & Mean & Median & Std \\
\hline BA & schwefel & $\mathrm{D}=10 \mathrm{~Np}=20$ & 1959.602247 & 3289.229564 & 2725.59624 & 2727.627 & 279.3531 \\
\hline HBA & schwefel & $\mathrm{D}=10 \mathrm{~Np}=20$ & 713.664254 & 1761.422227 & 1137.196604 & 1129.726 & 302.4351 \\
\hline BA & schwefel & $\mathrm{D}=10 \mathrm{~Np}=30$ & 2256.802075 & 3108.460391 & 2685.240477 & 2684.772 & 208.3854 \\
\hline BA & schwefel & $\mathrm{D}=20 \mathrm{~Np}=20$ & 5465.207747 & 6767.540433 & 6186.573044 & 6163.477 & 298.6477 \\
\hline HBA & schwefel & $\mathrm{D}=20 \mathrm{~Np}=20$ & 1764.423571 & 3815.612049 & 2839.429654 & 2916.921 & 527.6105 \\
\hline BA & schwefel & $\mathrm{D}=20 \mathrm{~Np}=30$ & 5414.22199 & 6736.635909 & 6233.538811 & 6275.883 & 311.5135 \\
\hline
\end{tabular}

Table 13: Statistical based Comparative Analysis of Sphere Function

\begin{tabular}{|l|c|c|c|c|c|c|c|}
\hline Alg. & Bench. & Meas. & Min & Max & Mean & Median & Std \\
\hline BA & sphere & $\mathrm{D}=10 \mathrm{~Np}=20$ & 2.835117732 & 21.16130085 & 10.67777626 & 8.936861 & 5.673571 \\
\hline HBA & sphere & $\mathrm{D}=10 \mathrm{~Np}=20$ & $2.82199 \mathrm{E}-15$ & $9.43268 \mathrm{E}-14$ & $2.20982 \mathrm{E}-14$ & $9.85 \mathrm{E}-15$ & $2.22 \mathrm{E}-14$ \\
\hline BA & sphere & $\mathrm{D}=10 \mathrm{~Np}=30$ & 1.728915327 & 19.1461846 & 9.608488422 & 9.373496 & 4.9299 \\
\hline BA & sphere & $\mathrm{D}=20 \mathrm{~Np}=20$ & 4.70684935 & 39.20025809 & 15.64143313 & 13.00739 & 9.109928 \\
\hline HBA & sphere & $\mathrm{D}=20 \mathrm{~Np}=20$ & $1.32526 \mathrm{E}-17$ & $9.20161 \mathrm{E}-15$ & $1.45096 \mathrm{E}-15$ & $2.92 \mathrm{E}-16$ & $2.56 \mathrm{E}-15$ \\
\hline BA & sphere & $\mathrm{D}=20 \mathrm{~Np}=30$ & 1.420018171 & 42.61122137 & 17.32465154 & 15.06807 & 10.64779 \\
\hline
\end{tabular}

Table 14: Statistical based Comparative Analysis of Whitley Function

\begin{tabular}{|l|c|c|c|c|c|c|c|}
\hline Alg. & Bench. & Meas. & Min & Max & Mean & Median & Std \\
\hline BA & whitley & $\mathrm{D}=10 \mathrm{~Np}=20$ & 93390.94528 & 114047414.7 & 18348589.16 & 11068826 & 25972973 \\
\hline HBA & whitley & $\mathrm{D}=10 \mathrm{~Np}=20$ & 18.07292823 & 60.03289276 & 41.13330325 & 43.39945 & 10.67432 \\
\hline BA & whitley & $\mathrm{D}=10 \mathrm{~Np}=30$ & 2567.358656 & 93314625.34 & 19248524.17 & 10458668 & 24097765 \\
\hline BA & whitley & $\mathrm{D}=20 \mathrm{~Np}=20$ & 2461923.754 & 290671465.9 & 71254935.68 & 47193820 & 74979817 \\
\hline HBA & whitley & $\mathrm{D}=20 \mathrm{~Np}=20$ & 150.2285584 & 350.5333379 & 243.5080122 & 245.4359 & 40.69101 \\
\hline BA & whitley & $\mathrm{D}=20 \mathrm{~Np}=30$ & 1591392.813 & 417382556.6 & 96891183.93 & 61383259 & $1.12 \mathrm{E}+08$ \\
\hline
\end{tabular}

Further, the Table $5-14$ presents the exclusive statistical analysis of benchmark function used for optimization. All the benchmark functions are tested and validated with the same set of machines as displayed in the Table $1-4$. During the experimentation the statistical parameters such as min, max, mean, standard deviation and median are calculated.

\section{CONCLUSION}

This paper is concluded by proposing a novel cloud resource management using Social Bat Algorithm. The experimental results shows that the demand in the resource leads to increased amount of traffic overload. To address this issue, various optimization algorithms are proposed. The purpose of optimization algorithm is to find the best and optimal solution out of the other solutions. In this regard, Particle Swarm Optimization is considerable producing promising results as of now. However, the problem with the existing PSO based algorithms suffers due to convergence problem and it is not suitable for multi- objectives. To address this issue, this paper proposed a novel hybrid algorithm called Social Bat Algorithm.

The HBA used in this paper considers the resource allocation and achieves multi-objective functionality without any convergence. The proposed HBA solved the major problem of resource provisioning and cost reduction. The proposed HBA also proves that the cost estimation for the HBA is comparatively less than the existing state of the art models. Finally, when compared with the other work such as parallel genetic algorithm, NSGA algorithms, the proposed HBA is best in terms of processing, execution etc.

\section{REFERENCES}

[1] M. A. Rodriguez and R. Buyya, "Deadline Based Resource Provisioning and Scheduling Algorithm for Scientific Workflows on Clouds," In IEEE Transactions on Cloud Computing, vol. 2, no. 2, pp. 222-235, 1 April-June 2014. 
[2] Q. Zhang, M. F. Zhani, Y. Yang, R. Boutaba and B. Wong, "PRISM: Fine-Grained Resource-Aware Scheduling for MapReduce," In IEEE Transactions on Cloud Computing, vol. 3, no. 2, pp. 182194, 1 April-June 2015.

[3] X. Zhu, L. T. Yang, H. Chen, J. Wang, S. Yin and $X$. Liu, "Real-Time Tasks Oriented Energy-Aware Scheduling in Virtualized Clouds," In IEEE Transactions on Cloud Computing, vol. 2, no. 2, pp. 168180, April-June 2014.

[4] T. Tran, B. Vo, T. T. N. Le, N. T. Nguyen, "Text clustering using frequent weighted utility itemsets", Cybern. Syst., vol. 48, no. 3, pp. 193-209, Mar. 2017.

[5] M. Quadrana, A. Bifet, R. Gavaldà, “An efficient closed frequent itemset miner for the MOA stream mining system", AI Commun., vol. 28, no. 1, pp. 143-158, Jan. 2015.

[6] H. Huang, "Fusion of Modified Bat Algorithm Soft Computing and Dynamic Model Hard Computing to Online SelfAdaptive Fuzzy Control of Autonomous Mobile Robots", In IEEE Transactions on Industrial Informatics, vol. 12, no. 3, pp. 972-979, June 2016.

[7] W. Dong, M. Zhou, “Gaussian classifierbased evolutionary strategy for multimodal optimization", IEEE Trans. Neural Netw. Learn. Syst., vol. 25, no. 6, pp. 1200-1216, Jun. 2014.

[8] R. Boutaba, L. Cheng, Q. Zhang, “On cloud computational models and the heterogeneity challenge", J. Internet Serv. Appl., pp. 1-10, 2012.

[9] D. Xie, N. Ding, Y. Hu, R. Kompella, “The only constant is change: Incorporating time-varying network reservations in data centers", Proc. ACM SIGCOMM, pp. 199210, 2012.

[10] G. Juve, A. Chervenak, E. Deelman, S. Bharathi, G. Mehta, K. Vahi, "Characterizing and profiling scientific workflows", Future Generation Comput. Syst., vol. 29, no. 3, pp. 682-692, 2012.

[11] S. Pandey, L. Wu, S. M. Guru, R. Buyya, "A particle swarm optimization-based heuristic for scheduling workflow applications in cloud computing environments", Proc. IEEE Int. Conf. Adv. Inform. Netw. Appl., pp. 400-407, 2010.

[12] D. Sharma, A. Chatterjee, A. Rakshit, "A hybrid approach for design of stable adaptive fuzzy controllers employing
Lyapunov theory and particle swarm optimization", IEEE Trans. Fuzzy Syst., vol. 17, no. 2, pp. 329-342, Apr. 2009.

[13] Chandra Sekhar Reddy, N. Purna Chandra Rao Vemuri, Govardhan, A. An Emperical Study on Support Vector Machines for Intrusion Detection, International Journal of Emerging Trends in Engineering Research, Vol. 7, No. 10, pp. 383-387, October 2019.

[14] Rufo I. Marasigan Jr, Alvin Sarraga Alon, Mon Arjay F. Malbog, Joshua S. Gulmatico, Copra Meat Classification using Convolutional Neural Network, International Journal of Emerging Trends in Engineering Research, Vol. 8. No. 2, February 2020

[15] Subramaniyam, S, Performance Analysis on Diesel Engine using Neem and Soya Bean Oil, International Journal of Emerging Technologies in Engineering Research (IJETER), Vol. 5, Issue 8, August 2017. 